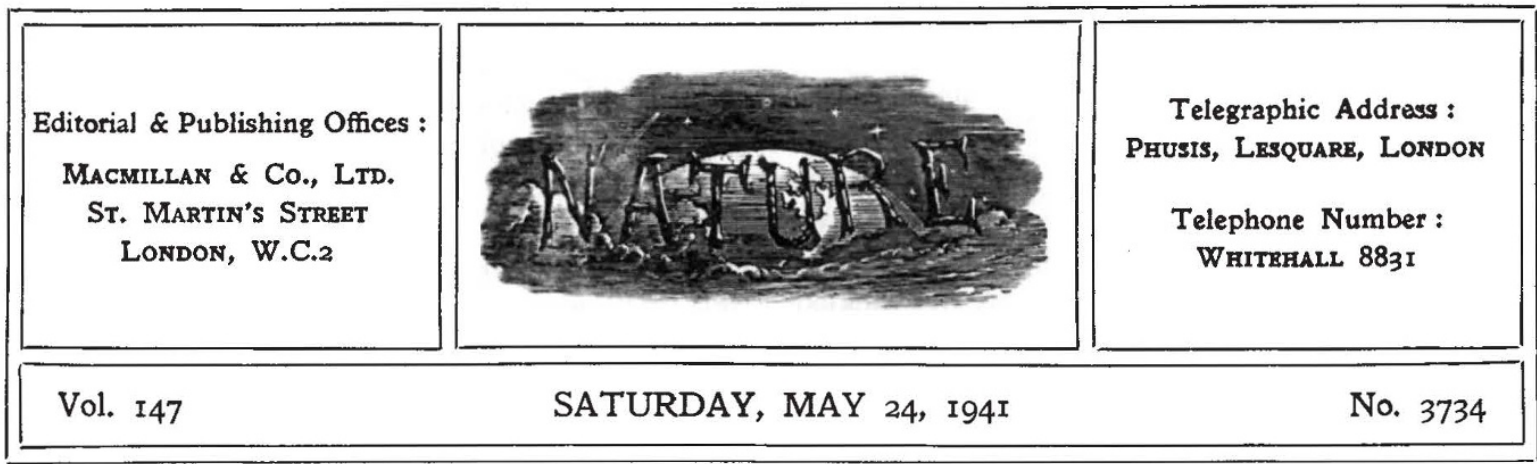

\title{
REGIONALISM IN ADMINISTRATION
}

$\mathrm{T}^{\mathrm{H}}$ $\mathrm{HE}$ extension of rationing, the concentration of industry, the changes in reserved occupations, and the registration of women must have brought home to everyone the vital part which the civilian population has to play in the present struggle; but that contribution must be seen in its true perspective. Whether in offence or defence, the striking power of the armed forces depends upon the maintenance of supplies. That is not a matter for the armament factories alone; it involves also the agricultural worker and others concerned with food production, and those who operate the transport services and other essential services in our industrial and national life. It is for the Government to determine as wisely as possible the exact balance between the distribution of man-power in the armed forces, munitions and other essential services for maintaining the national life, and this the policy of concentration and limitation of supplies is designed to promote. Once that balance has been struck, the development of full fighting power depends primarily upon maintaining health and morale and the maximum efficiency. Enemy air attacks on Great Britain have been directed as much against health and morale as against production.

Political and Economic Planning (P E P) has recently issued a valuable broadsheet entitled "London under Bombing", which directs attention not only to important specific issues but also to the wider problems involved in the readjustments of its life that the civil population is being compelled to make, and it does not fail to point out that in this greater plasticity lies one hope of the emergence of a better order. Artificial administrative boundaries, especially between the various parts of a single large town or urban cluster, can no longer be maintained. Regional organization of local services is gaining strength, and local organization is losing it. The whole-time administrator responsible to a higher authority is replacing the spare-time committeeman responsible to voters who may or may not vote occasionally either for or against him. The rigidity of class barriers has been diminished in the armed forces, in civil defence services, through evacuation schemes and otherwise, and the lack of balance between the material and the spiritual values of civilization has been sharply redressed. The nation has learnt that a vigorous social purpose is not only a source of satisfaction but also a source of strength and comfort.

Contrasting the experience of bombing with anticipations, the broadsheet refers to the way in which some technical surprises have played a part in determining the nature of London's problems during the last few months. The extensive use of the delayed action bomb has resulted in some unexpected transport problems due to traffic diversions, and in large numbers of temporarily homeless persons. It has also shown that bomb disposal squads were understaffed. Bombing has also stressed not only weaknesses in the civil defence services but also weaknesses in the whole system of the government of London. The existence of ninety-five separate local government authorities in the London Civil Defence Region has not led to the most effective action in dealing with the social consequences of bombing.

Once the Blitzkrieg has failed, the objective of enemy attack, as already indicated, becomes the general dislocation of war effort. The task of civil defence is to take the necessary steps to minimize the harmful effect of attack, and to put into action wider measures required to adapt the civilian population to an environment partly conditioned to the danger of attack.

With regard to direct action, the only possible 
generalization is that the A.R.P. services have worked well. A suggestion which calls for careful consideration is the provision of a service of welfare wardens whose business would be to reach the scene of an 'incident' as quickly as possible in order to direct people to rest centres, and look after the needs of those who take temporary refuge elsewhere. Such a service is actually in operation in Birmingham and some other provincial cities, and it might be embodied in the existing wardens' organizations. Other provisions to deal with social rather than physical casualties also require strengthening. Rest centres, billeting, re-housing and house-repairs have an important contribution to make to the maintenance or restoration of health and morale.

With regard to shelters, criticism in the last six months has been directed more at the low standard of amenity than at the low standard of protection. If a policy of dispersal had been faithfully followed in practice, there would have been no amenity problem. While in many shelters opportunities for communal activity have been used, and attention is being given to recreation and study-more than four hundred evening classes are being run in shelters by the L.C.C.- the most important aspect of the provision of amenities is that of health.

The seriousness of this question of health is well brought out by one of the most important sections of the broadsheet. It is not merely that many thousands of Londoners spend their nights either in overcrowded, uncomfortable and dirty public shelters, or in cold and damp shelters of the Anderson type. The resistance of Londoners to illness is also being reduced by rising food prices and rationing, by longer hours and less holidays. Moreover, bombing constitutes a direct threat to health through damage to water-mains and sewers, leading to risk of the dissemination of typhoid and paratyphoid fevers. The interruption of services such as water, gas and electricity leads to lower standards of cleanliness and personal hygiene.

The impairment of individual resistance in ways such as these, coupled with the depletion of health services by withdrawal of personnel or commandeering of premises, is likely to lead to unusually widespread dissemination of air-borne infections, especially coughs and colds, influenza and pneumonia, streptococcal infections and cerebrospinal fever. Up to the end of 1940, the condition of London in respect of air-borne infections was generally satisfactory. None the less, abatement of overcrowding by providing more shelter space and air per person, disinfecting the air and mechanical obstruction of the dissemination of respiratory 'droplets' by the use of mouth masks are measures which should be encouraged.

Besides such measures in the shelters, there are broader measures of combating infection. Resistance to infection could be built up by measures of mass immunization as well as by protective foods and adequate rest, and the chances of infection should be minimized by intercepting infectious cases before they reach the public shelters, as well as by detecting infectious cases in the shelters and isolating them as quickly as possible. The importance of communal feeding in maintaining individual resistance under these conditions is obvious. This question involves close co-operation with the Ministry of Food as well as with the Welfare Department of the Ministry of Labour and National Service.

The problem of health, like that of evacuation or of industrial mobilization, cannot be dealt with in isolation. It must be handled against the broader background of the national life. The needs of the inhabitants of large cities under intensive air attack cannot be satisfied by having regard to their private lives alone. We must take into account also their working conditions and the conditions under which they travel to their work. Communal feeding, and even the Ministry of Food's scheme for supplying meals in London shelters, should not be considered entirely without reference to industrial canteens, the use of mobile canteens, and the exigencies of rationing imposed from time to time by the food situation.

Such complexities as these are responsible for the strain which is being placed on administration, whether in regard to the maintenance of such public services as transport, water, gas or electricity supply, and the institution of repairs when needed, or in the extent of the resources and ability which the present local government units have at their disposal. The PEP broadsheet points to one conspicuous gap in the field of utilities, namely, the absence of organization to deal with salvage, particularly commodities, and also stresses the need for some greater sharing of disposable revenues in the London boroughs. More effective linking of regional and local executive officers is also clearly required, and there has already been a marked tendency to rely on regional administration where local administration has proved ineffective. 
The broadsheet shows very clearly the impetus to regionalism which the impact of bombing on London has given, and the opportunity for general reorganization which has been provided. Continuous research into such problems might well lead to an effective combination of regionalism with democratic devolution of responsibility. Any breakdown of traditional social arrangements, notably the medical services, and the finance of local government, should lead to their radical overhaul. The decentralization of industry and public administration may have a profound effect on the future economic and social structure of Britain, while the part played by the civil population in defence of their homes and work-places expresses a conception of public service which should find a permanent place in the national life of the country.

\section{SUICIDE OF THE HUMANITIES}

\section{To Hell with Culture}

Democratic Values are New Values. By Herbert Read. (The Democratic Order, No. 4.) Pp. 64. (London: Kegan Paul and Co., Ltd., 1941.) 1s. net.

$\mathrm{T}$ HIS may not seem an appropriate place to review a book in which the word science is never mentioned, and from which the very conception of scientific activity is totally absent. But, as recent correspondence in NATURE has shown, many men of science feel themselves a part of the cultural tradition of our civilization, and they cannot be expected to remain unmoved at the spectacle of so respected a critic as Mr. Read committing hara-kiri in the name of culture as a whole. At least they may look to their spiritual pharmacopœia to see if there is not some remedy which they can prescribe for the patient.

Mr. Read has little difficulty in demonstrating that 'culture', in the conventional sense of painting easel pictures and writing poems, is in a bad way, and has degenerated into a mere decorative veneer plastered over the realities of our daily lives. Men of science, however, will be tempted to point out that our civilization is now dependent on scientific techniques at every point, equally in the most fundamental matters such as food-raising and in the most superficial titbits such as the colours of ladies' lips, and that a culture which forgets its scientific components is obviously foredoomed to evaporate into hot air. It is perhaps because Mr. Read does uncompromisingly omit any reference to scientific thought that his suicide is so clearly 'while of unsound mind'.

He begins by defining democracy as being the realization of the three fundamental tenets of communist economics: production for use, from each according to his ability, to each according to his needs, and the ownership of industry by the workers. This may be rather like defining a rose as a heavy soil and plenty of farmyard manure; but let that pass. He proceeds to his most valuable and profound point, that a living democratic culture is an attitude of mind which permeates and fertilizes every activity of every individual ; it is not a thing apart, to be tasted only on Sunaay afternoon excursions to the museums, but is a flame perpetually burning in the mind. A valid culture, he says, must be there in the fingertips of a potter as he throws an ordinary beer-mug on the wheel ; it is an example to catch the imagination of the Neolithic craftsman rather than of our present industrial proletariat, but the point it is making is one which must be the very basis of a modern democratic civilization.

There is here, surely', a promising line of attack on one of the problems facing men of science to-day, namely, how far they should take up definitely political or administrative work. From a long-term point of view at least, the mode of operation of a cultural activity such as science should be through its influence on the general outlook and presuppositions of the ordinary man. The social function of a good man of science is not to become a bad administrator, but to encourage and direct the scientific interests of his fellow citizens, from politicians to washerwomen.

When Mr. Read attempts to show concretely what the inspiration of culture would mean in daily life, he produces only an out-and-out functionalist theory of æsthetic value. But is this everpresent culture really no more than an attention to function? A bronze Han amphora holds no more wine, and holds it no better, than the crudest Brummagem jug. Without claiming to have any special qualifications of æsthetic training, one may wonder whether the motor-cars which Mr. Read finds so satisfactory have any more claim to beauty than a fashionable 'Vogueish' elegance. Efficiency is an ingredient in beauty, perhaps even a prerequisite for its creation. The invention of the internal combustion engine made it impossible to go on designing the most beautiful vehicles yet made by man, the Victorian hay waggons and carriages, just as the steam engine put the clipper ship into the category of an out of date genre. A 